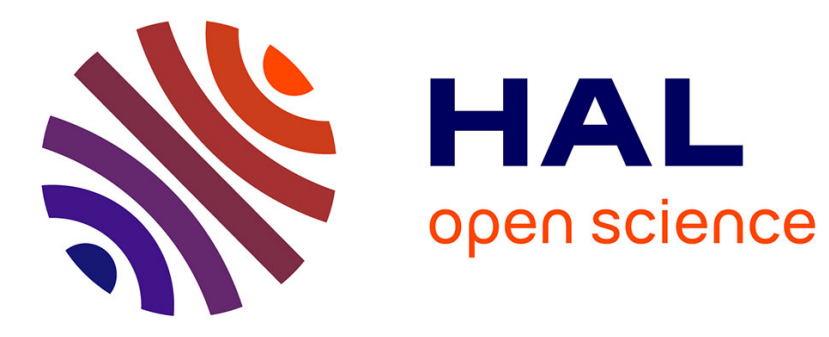

\title{
Meticillin-resistant (MRSA): screening and decolonisation
}

Barry Cookson, Marc J.M. Bonten, Fiona M. Mackenzie, Robert L. Skov, Henri A. Verbrugh, Evelina Tacconelli

\section{- To cite this version:}

Barry Cookson, Marc J.M. Bonten, Fiona M. Mackenzie, Robert L. Skov, Henri A. Verbrugh, et al. Meticillin-resistant (MRSA): screening and decolonisation. International Journal of Antimicrobial Agents, 2011, 37 (3), pp.195. 10.1016/j.ijantimicag.2010.10.023 . hal-00671242

HAL Id: hal-00671242

https://hal.science/hal-00671242

Submitted on 17 Feb 2012

HAL is a multi-disciplinary open access archive for the deposit and dissemination of scientific research documents, whether they are published or not. The documents may come from teaching and research institutions in France or abroad, or from public or private research centers.
L'archive ouverte pluridisciplinaire HAL, est destinée au dépôt et à la diffusion de documents scientifiques de niveau recherche, publiés ou non, émanant des établissements d'enseignement et de recherche français ou étrangers, des laboratoires publics ou privés. 


\section{Accepted Manuscript}

Title: Meticillin-resistant Staphylococcus aureus (MRSA): screening and decolonisation

Authors: Barry Cookson, Marc J.M. Bonten, Fiona M. MacKenzie, Robert L. Skov, Henri A. Verbrugh, Evelina Tacconelli

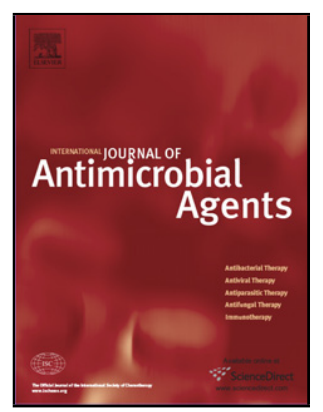

PII: S0924-8579(10)00496-6

DOI:

Reference: doi:10.1016/j.ijantimicag.2010.10.023

ANTAGE 3477

To appear in: International Journal of Antimicrobial Agents

Received date: $\quad 15-10-2010$

Accepted date: $\quad 18-10-2010$

Please cite this article as: Cookson B, Bonten MJM, MacKenzie FM, Skov RL, Verbrugh HA, Tacconelli E, Meticillin-resistant Staphylococcus aureus (MRSA): screening and decolonisation, International Journal of Antimicrobial Agents (2010), doi:10.1016/j.ijantimicag.2010.10.023

This is a PDF file of an unedited manuscript that has been accepted for publication. As a service to our customers we are providing this early version of the manuscript. The manuscript will undergo copyediting, typesetting, and review of the resulting proof before it is published in its final form. Please note that during the production process errors may be discovered which could affect the content, and all legal disclaimers that apply to the journal pertain. 


\section{Meticillin-resistant Staphylococcus aureus (MRSA): screening and decolonisation}

Barry Cookson ${ }^{a, \star}$, Marc J.M. Bonten ${ }^{b}$, Fiona M. MacKenzie ${ }^{c}$, Robert L. Skov ${ }^{d}$, Henri A. Verbrugh ${ }^{e}$, Evelina Tacconelli ${ }^{\dagger}$

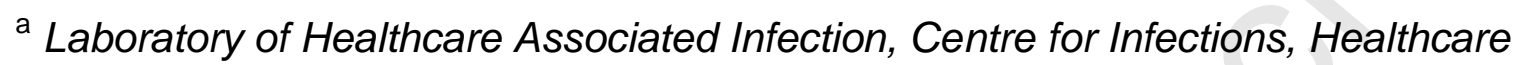
Protection Agency, 61 Colindale Avenue, London NW9 5EQ, UK

${ }^{\mathrm{b}}$ Department of Mathematics, Utrecht University, Utrecht, The Netherlands

${ }^{\mathrm{c}}$ Medical Microbiology, Aberdeen Royal Infirmary, Aberdeen, UK

${ }^{\mathrm{d}}$ National Centre for Antimicrobials and Infection Control, Statens Serum Institut, Copenhagen, Denmark

${ }^{\text {e }}$ Department of Medical Microbiology and Infectious Diseases, Erasmus University Medical Centre, Rotterdam, The Netherlands

${ }^{\dagger}$ Department of Infectious Diseases, Università Cattolica del Sacro Cuore, Milan, Italy

ARTICLE INFO

Article history:

Received 15 October 2010

Accepted 18 October 2010

Keywords:

Infection control

MRSA

Screening 
* Corresponding author. Tel.: +44 208327 7249; fax: +44 2082007449.

E-mail address: barry.cookson@hpa.org.uk (B. Cookson). 


\section{ABSTRACT}

Meticillin-resistant Staphylococcus aureus (MRSA) infections are of increasing importance to clinicians, public health agencies and governments. Prevention and control strategies must address sources in healthcare settings, the community and livestock. This document presents the conclusions of a European Consensus Conference on the role of screening and decolonisation in the control of MRSA infection. The conference was held in Rome on 5-6 March 2010 and was organised jointly by the European Society of Clinical Microbiology and Infectious Diseases (ESCMID) and the International Society of Chemotherapy (ISC). In an environment where MRSA is endemic, universal or targeted screening of patients to detect colonisation was considered to be an essential pillar of any MRSA control programme, along with the option of decolonising carriers dependent on relative risk of infection, either to self or others, in a specific setting. Staff screening may be useful but is problematic as it needs to distinguish between transient carriage and longer-term colonisation. The consequences of identification of MRSA-positive staff may have important effects on morale and the ability to maintain staffing levels. The role of environmental contamination in MRSA infection is unclear, but screening may be helpful as an audit of hygiene procedures. In all situations, screening procedures and decolonisation carry a significant cost burden, the clinical value of which requires careful evaluation. European initiatives designed to provide further information on the cost/benefit value of particular strategies in the control of infection, including those involving MRSA, are in progress. 


\section{Introduction}

Whilst the problem of antimicrobial resistance is widespread among common bacterial pathogens, the particular health threat caused by meticillin-resistant Staphylococcus aureus (MRSA) is of increasing concern to clinicians, public health agencies, governments and, last but not least, the general public. This has brought critical attention to bear on the adequacy of current infection prevention and control strategies, which have had to take into account reservoirs of MRSA in healthcare delivery institutions [healthcare-associated MRSA (HCA-MRSA)] and, more recently, the community [community-acquired/associated MRSA (CA-MRSA)] and livestock [livestock-associated (LA-MRSA)] [1-6]. For these reasons, the European Society of Clinical Microbiology and Infectious Diseases (ESCMID) and the International Society of Chemotherapy (ISC) organised a joint expert meeting to focus on the latest evidence for MRSA prevention and control measures and treatment in Rome, Italy, in March 2010. This review is based on the proceedings of that meeting.

In particular, this document outlines specifically the opinions expressed by experienced clinicians and scientists on the role of screening and decolonisation as useful tools in such management strategies. Low prevalence countries were not considered a major issue: they have very similar screening policies. In our opinion, the target audience for this document should include health policy-makers, infection control teams, and clinicians working in hospitals with endemic MRSA, i.e. a situation where MRSA transmission rates are high and MRSA is constantly being circulated amongst the population present in the hospital and re-introduced by patients previously admitted to the same or other institutes in a locality/region where MRSA is endemic [7]. Indications for screening and decolonisation are not necessarily 
uniformly directed at every hospital within any given country. A recurrent and important feature since MRSA was first reported in the early 1960s has been that hospitals can vary in their MRSA rates, not just between countries but within a country or even in the same city $[8,9]$.

However, it is important to harmonise infection prevention and control measures between hospitals to limit MRSA spread between them, and a good example of such harmonisation is to ensure that hospitals inform one another when they transfer MRSA-affected patients between their institutions [10-12].

Screening involving the use of microbiological procedures to detect the carriage of MRSA by individuals without evidence of clinical infection is an essential 'pillar' of any MRSA control programme [13-15]. Since such procedures carry significant healthcare costs, it follows that any surveillance undertaken be of proven benefit to the overall strategies put in place for the prevention and control of MRSA infections. This is often difficult to ascertain, as such procedures are frequently multifaceted and analysing the contribution of any one component to observed outcomes can, in practice, be extremely difficult [16].

However, it was stressed that some sort of MRSA screening is essential in order to be successful in MRSA prevention and control. When considering the design of such a screening programme, it is essential to be aware of the context, specifically the MRSA occurrence levels nationally, regionally and locally. It is vital that nationallyagreed guidance is incorporated into local policies and that relevant practices are audited regularly (this is also called process surveillance) to ensure that there is 
compliance. Policies may need to be modified locally based on the results of these audits so that they remain fit for purpose. This is especially pertinent given the changing landscape in Europe with the emergence of CA-MRSA and LA-MRSA.

\section{Universal and targeted screening}

'Who' should be screened for MRSA as well as 'where' and 'when' are still open questions. Several sites are recommended when screening patients. The anterior nares are the 'headquarters' of $S$. aureus/MRSA carriage and should always be included, although some data suggest that CA-MRSA may not be carried in the nose as frequently as other MRSA [4]. Data from community outbreaks suggest that skinto-skin, and to a lesser extent skin-to-fomite, contacts represent common routes of transmission [17]. The throat is also important, especially where relapse following eradication therapy is to be explored (see below). Additional sites are often included but may have diminishing returns. The perineum is more frequently colonised by CAthan by HCA-MRSA strains [18]. Other sites include any lesions, manipulated sites (such as intravenous and urinary catheters), the axillae, the fingertips and the hairline. The latter two sites can provide clues that patients are dispersers with an increased risk of transmission to other patients, family members or the wider environment around patient areas or the home $[19,20]$. Pooling swabs from several sampling sites into a single broth culture has long been advocated as a cost-effective screening method where one just wants to know whether, rather than where, subjects are positive [21]. 
Both in primary detection and in screening following decolonisation, the use of selective or semiselective broth culture of individual swabs has been shown to increase the sensitivity of detection $[21,22]$.

In hospitals with endemic MRSA, universal screening of all individuals admitted to the healthcare facility as well as isolation and/or decolonisation of patients screened MRSA-positive are indicated to be the most effective interventions in mathematical models [12] and, in support of this theoretical approach, have been associated with significant reductions in the incidence of MRSA infection in clinical studies [23,24]. However, the efficacy and cost effectiveness of universal screening, being strictly related to the local epidemiology of MRSA infections, continues to require clarification [25-28]

Screening can also enable closer monitoring of circulating bio/genotypes. Recording typical antimicrobial susceptibility patterns and variants of these can inform the utility for local 'antibiogram typing' and treatment options. Screening also produces alert organism data, raising possible issues of MRSA occurring in patients without previous hospitalisation, for example livestock exposure in MRSA-positive patients $[29,30]$.

The study that best represents an example of the efficacy of universal screening is that performed by Robicsek et al. [23] at a three-hospital organisation in the USA with ca. 40000 annual admissions. The authors performed an interventional study comparing rates of MRSA clinical disease during and after hospital admission in three consecutive periods: (i) baseline (12 months); (ii) MRSA screening of all 
admissions to the Intensive Care Unit (ICU) (12 months); and (iii) universal MRSA screening of all hospital admissions, with contact isolation and decolonisation of MRSA-positive cases (21 months). During the last universal screening period, the prevalence of MRSA infections decreased significantly compared with the baseline ($70 \%)$. However, some limitations of the study need to be emphasised: findings relied on observational data only; and MRSA isolation days and adherence and effectiveness of decolonisation were not monitored.

The alternative to active universal screening is selective (targeted) screening, which takes into account the relative risk to a patient, and others, on the basis of the individual's medical history, the procedure(s) to be undertaken during hospitalisation and the incidence of MRSA colonisation in the community of which they are part [31]. West et al. [32] performed a before-and-after study comparing the rate of MRSA infection before and after the initiation of expanded surveillance in a community hospital system in the USA. Patients considered to be at risk were those who were (a) transferred from another hospital, (b) admitted from long-term care facilities, (c) re-admitted within 30 days after discharge and (d) admitted to a nephrology service. Cost effectiveness was calculated as the difference between the cost savings associated with preventing nosocomial MRSA bacteraemia and surgical-site infections (SSIs) and the cost of MRSA cultures and contact isolation for patients colonised with MRSA. The mean rate of nosocomial MRSA infection decreased over the study period. Surveillance was cost effective, preventing 13 nosocomial MRSA bacteraemias and 9 SSIs, resulting in a saving of US\$1 545762 [32]. 
Table 1 summarises risk factors to be considered when planning a targeted screening programme. International transfers are becoming a higher priority in many countries with the presence of CA-MRSA and its spread within hospitals causing serious healthcare-associated infections. In some countries, exposure to LA-MRSA is a significant risk, whilst in others it has yet to be described. To improve compliance with MRSA screening policies, we recommended the flagging of MRSA-positive status in the patient's notes or the use of computerised systems that enable one to readily 'tag' MRSA-positive patients and follow these up accordingly. Such a system was described many years ago but may not be available in many hospitals [33].

This selective approach to screening has the undoubted advantage of reduced cost and workload but requires constant vigilance. Over time, changes in those considered to be in at-risk groups may be needed based on monitoring of the incidence of infection in a particular establishment or clinical unit. For example, the National Health Service (NHS) Quality Improvement Scotland Health Technology Assessment (HTA) on the clinical and cost effectiveness of MRSA screening originally recommended screening all overnight admission [34]. When this strategy was tested, however, the Scottish recommendations were altered to include screening of the majority of elective admissions to acute specialties (excluding paediatrics, obstetrics and psychiatry) and elective admissions to only four specialties (nephrology, vascular surgery, dermatology and care of the elderly) that were identified as having the highest prevalence of MRSA colonisation $[35,36]$.

Up-scaling selective screening to universal admission screening may be necessary during an outbreak situation in order to differentiate between imported and unrelated 
cases [positive culture/polymerase chain reaction $(\mathrm{PCR}) \leq 48 \mathrm{~h}$ of admission] and new cases of hospital-acquired colonisation or infection that are part of the outbreak (first positive culture/PCR $>48 \mathrm{~h}$ after admission). This differentiation is essential for monitoring the effect of infection control measures.

The surveillance strategies discussed so far have concentrated on hospital admissions. However, consideration must be also given to cross-transmission of MRSA both by patients and staff. With both groups it is important to distinguish between transient/short-term carriage, longer-term carriage and established colonisation, particularly in the case of staff [37]. This is often ignored in studies $[38,39]$. In the case of patient transfer screening, two distinct possibilities should be considered: either recognising the risk to patients from a low-dependency medical ward when transferred to high-dependency or surgical wards with an increased chance of auto-infection as a result of invasive procedures; or that of risk to vulnerable patients on these units posed by an incoming carrier of MRSA (crossinfection). Furthermore, even without internal transfer, there is an increased risk of colonisation of patients previously free of MRSA as a result of long-term hospitalisation and antibiotic therapy [40] and, in some situations, regular screening of such patients will be useful. Clearly this strategy would involve significant added workload and cost and, therefore, the definition of long-term stay and the resulting frequency of screening would need to be examined carefully with regard to costbenefit in a particular institution.

Whatever the chosen MRSA screening procedure pursued, which in the case of England and Wales in the UK is mandatory screening of elective surgery patients 
prior to admission with the imminent addition of emergency admissions, it is implicit in any strategy that it be followed by timely action based on the results as part of agreed infection prevention and control procedures. Furthermore, it is essential that there are continuing audits of compliance with screening procedures, together with assessments of the speed and effectiveness of responses to screening results [41]. As already stated, screening for MRSA is pivotal to any strategy for MRSA prevention and control. For example, it enables interpretation of the impact of suppressive, decontamination and isolation strategies. As with healthcare-associated infection surveillance, MRSA screening should provide information for action. Increasingly in these cost-conscious times, it is vital that we consider the cost effectiveness and cost utility of MRSA screening and the intervention measures it informs. Diverting resources to screening may, for example, have a detrimental effect on patient safety or the quality of patient care.

\section{Screening after hospital discharge}

Discharge/follow-up screening and decolonisation of specific patients may be appropriate to break the feedback loop of colonisation/infection that may occur when patients who remain colonised are re-admitted to hospital $[42,43]$. Patients for whom there is considered to be a significant risk of acquiring MRSA during hospitalisation should be screened on discharge, and more so if they are expected to be re-admitted to hospital in the future, especially given that MRSA colonisation can be prolonged for periods of $>12$ months. Once identified as MRSA-positive, flagging of patient's notes (computerised if possible) may be adequate for some patients. For others, especially where they may be discharged to other care facilities, decolonisation 
following an assessment of the likelihood of its success is the best course of action [2].

\section{Isolation and decolonisation}

Once MRSA colonisation/infection is detected, contact isolation should be implemented to prevent cross-transmission. Physical isolation of patients found to be colonised with MRSA on admission into a separate unit has two key advantages: it establishes a physical barrier for transmission of MRSA between an MRSA-positive patient and other patients; and it highlights the precautions necessary for healthcare workers (HCWs) and visitors to follow [2,7]. In an ideal world, all MRSA-positive patients should be isolated with designated nursing staff. However, where there is only limited capacity, a risk assessment undertaken to determine which patients require isolation (with or without their own nursing staff), based on the likelihood of transmission, is necessary. In this regard, patients with underlying skin diseases such as eczema who are more likely to shed large numbers of MRSA into the environment should be given priority. Recent mathematical modelling strongly suggests that both in endemic and epidemic settings of MRSA it is possible to reduce MRSA rates significantly by isolation and that this is cost effective even when the cost of the enhanced diagnostic and control measures is taken into account [8]. Various criteria for defining clearance exist, although at least three consecutive, weekly negative cultures is advised, assuming a sensitive broth enrichment method is used. In looking at the clinical and cost effectiveness of MRSA screening, the NHS Quality Improvement Scotland HTA recommended that patients identified as MRSApositive (colonised or infected) in a specialty deemed 'high risk' should be decolonised and isolated, whereas those in specialties considered as 'low risk' 
should be isolated but not decolonised [34]. However, when attempts were made to implement this strategy within the hospital, patient movement between low- and highrisk specialty wards made selective decolonisation problematic and a decision was taken to decolonise all MRSA-positive patients in Scotland $[35,36]$.

What regimens are available for consideration when attempting to eradicate MRSA from patients (or staff)? This is a difficult topic, like so many in MRSA epidemiology. Studies vary in quality of design and there is also no agreement on definitions and methods used, e.g. for how long should follow-up screening be performed, should sensitive broth culture techniques be used? Regimens have been well reviewed and these reviews point out that there were many good studies performed before data abstraction $[44,45]$.

Neomycin (with chlorhexidine) cream has been used for many years but its effectiveness has been queried and neomycin resistance is a potential problem. It still has a place where mupirocin resistance is an issue. The best evidence for effectiveness exists for mupirocin. Tea tree preparations appear to be more useful at skin sites but have not performed well in nasal MRSA clearance in a double-blind controlled comparison with mupirocin. Eradication of MRSA is far easier where there is just nasal carriage. Where there are skin lesions it is particularly problematic $[45,46]$.

Alternatives to mupirocin are needed and their effectiveness needs to be assessed robustly [47]. Use of mupirocin in the prevention and control of MRSA needs careful review. Its role in situations where MRSA occurrence is low is less problematic. 
However, frequent use carries a considerable risk of resistance, especially if this use is prolonged and repeated in individuals. Resistant strains can cross-infect and so risks may be particularly large in closed communities, such as healthcare establishments, as opposed to its use following patient discharge. The UK MRSA guidelines recommend its use in 'especially vulnerable pre-operative patients, such as those undergoing joint replacement, stent placement, vascular and cardiothoracic surgery or for patients in a unit where MRSA has a low prevalence and the intention is to eliminate the risk of spread.' Clearly mupirocin resistance monitoring is important. The UK MRSA guidelines $[44,45]$ have also reviewed other therapeutic options, including bacitracin, co-trimoxazole, rifampicin, tetracyclines and fusidic acid, which have demonstrated some efficacy (50-75\%), but these alternatives were not considered established clinical management. They also recommended that mupirocin should only be used with a systemically active agent in the treatment of patients with carriage, or infection, at extranasal sites.

The value of decolonisation of either MRSA-positive patients or HCWs remains in need of further clarification. The purpose of decolonisation can be considered either as the prevention of infection or the prevention of transmission. Although these two goals are closely linked, they comprise two different situations where the evidence for the net benefit of decolonisation is not yet established conclusively. Various potentially confounding issues have been identified. Patient lengths of stay are often very short and these pose challenges as post-discharge screening is required to confirm or refute the effectiveness of decontamination measures. This process can be facilitated to an extent by computerised, or patient note, flagging so that readmitted patients can be identified more readily and admission screening performed. 
Prevention of post-surgical infection in patients with colonised with MRSA deserves special attention. Recently, from the results of a randomised, double-blind, placebocontrolled study of 6771 surgical patients in five hospitals in The Netherlands, Bode et al. [48] concluded that rapid screening (real-time PCR assay) and immediate initiation of standard mupirocin and chlorhexidine decolonisation reduced the risk of nosocomial S. aureus infections by almost $60 \%$. However, all isolates of $S$. aureus in this study were susceptible to meticillin and mupirocin, confirming the low endemicity of MRSA in this country. In another recent study, specifically examining MRSA colonisation and infection, using a rapid, multiplex assay for detection, Harbarth et al. [41] were unable to demonstrate a decrease in nosocomial infection during the intervention period in a surgical ICU. The authors suggested a number of reasons for the observed outcome, including the fact that the MRSA infection rate at their centre was relatively low in the surgical department ( 0.36 cases/10 000 patient-days) and was therefore less likely to show a statistically significant effect of the intervention. Another proposed reason is that more than one-half (57\%) of the infected patients were MRSA-free on admission and acquired infection during hospitalisation. This indicated the limited value of admission screening for patients admitted for extended periods into surgical units of institutes where MRSA is endemic that do not perform weekly surveillance cultures. Furthermore, although using a rapid PCR-based test procedure for detection of MRSA, for $31 \%$ of patients the result was only available after surgery and $34 \%$ of patients with subsequent MRSA SSI did not receive antibiotic prophylaxis covering MRSA. To underline further the low level of available evidence, a recent systematic review and meta-analysis of the effect of MRSA detection by rapid screening tests on hospital-acquired MRSA infections and 
acquisition rates showed that screening using rapid molecular methods was not associated with a significant decrease in MRSA SSIs [49]. These conflicting reports add to the controversy regarding the clinical and cost-benefit of universal admission screening, as opposed to selective screening, and emphasise the need for more carefully designed and executed clinical studies to address these issues $[38,41,50-$ 54]. New studies in areas of high MRSA endemicity, or outbreaks, would provide invaluable data enabling evidence-based decision-making [24].

Before attempting patient (and staff) decolonisation, careful evaluation of the extent of carriage sites is required. Decolonisation is unlikely to succeed, or at least its success may be reduced considerably, if, for example, there are open wounds/lesions, intubation, external bone fixation, skin conditions such as colonised or infected eczema or burns, or affected urinary or intravascular catheters. For these patients it is necessary to consider the likelihood of recolonisation on wards where MRSA is endemic. Where relapse has occurred following attempted decolonisation, one needs to re-assess the patient. Typing isolates collected before and after decolonisation will assist on occasions when fresh acquisition is being considered. However, if there is insignificant variation in local epidemic MRSA, even by fine genetic typing, this will not help.

Another issue to be considered when planning a screening strategy is the development of mupirocin resistance. Higher risk has been reported to be related to age, throat carriage and the number of colonised sites [55]. However, in a recent systematic review the occurrence of resistance during treatment appeared to be extremely low [56]. 


\section{Staff screening}

Staff screening is a complex consideration both microbiologically and in terms of employee care. There are various categories of screening that have been considered, including: anonymous staff screening whilst on duty to encourage improved hand hygiene or to increase awareness [57]; pre-employment and agency staff screening; screening to plan eradication regimen design; and screening to confirm MRSA eradication. Although potentially contentious, there is also ad hoc screening of staff whilst on duty. If new MRSA cases are discovered from clinical specimens, or the patient screening strategies mentioned above, then amongst the possible causes one must consider staff-associated transmission. However, to be labelled as a carrier of MRSA will undoubtedly affect personnel morale and cooperation. In addition, temporary removal of staff from duty during decolonisation will result in difficulty in maintaining adequate staffing levels. Therefore, it is recommended to involve staff representative organisations in establishing screening and eradication procedures for doctors, nurses and others with close patient contacts. Despite these difficulties, a number of advantages of staff screening have been recognised both for patients and staff [38].

We recommend that HCWs are questioned regarding any infected or potentially contaminated skin lesions and to send such staff to occupational health departments for screening and case review. In such cases, and indeed whenever HCWs are to be screened, it is very important that they are screened at the commencement of duty, not during or at the end of duty. Such screening should be undertaken at least $12 \mathrm{~h}$ (and ideally at least 1 day) after a period of duty. This will reduce the chances of 
detecting HCWs who are transient carriers of MRSA and categorising them as colonised staff requiring decolonisation [58]. Once MRSA is detected in a HCW, repeat screening of the individual needs to be undertaken, again at least a day after being on duty. Typing of strains can be valuable for testing epidemiological hypotheses and to validate the success of intervention measures. Whilst the value of general staff screening remains to be determined by controlled studies, the contribution of such procedures to an infection control investigation of unexpected infection in a unit is likely to be positive, if isolated strains are fully typed.

Whether or not similar screening should be undertaken routinely in nursing homes or other long-term care facilities remains unclear. In the case of nursing homes in particular, the contribution of MRSA carriage and infection by companion animals also needs to be assessed, as many of the patients will have pressure sores or varicose ulcers requiring long-term wound management, often on a daily basis $[59,60]$.

\section{Environmental decolonisation}

It has been demonstrated that the immediate environment around patients is often positive for MRSA. This is especially important in ICUs where much of the equipment will become contaminated with MRSA [61]. Routine disinfection of such equipment and potentially contaminated surfaces is therefore part of the MRSA control bundle of measures. Yet the importance of environmental cleaning as a single measure within an infection control programme has never been quantified. Environmental sources of nosocomial pathogens have also been taken account of in the 'five moments for hand hygiene' described by the World Health Organization 
(http://www.who.int/gpsc/5may/background/5moments/en/index.html; accessed 27 September 2010) [62]

Screening is rarely required unless there is continuing transmission to previously MRSA-negative patients despite interventions including ensuring there is good compliance with environmental cleaning and hand hygiene for patient-related procedures. Screening of the environment should be informed by epidemiological clues, such as suspected spread via common bronchoscope usage amongst newly MRSA-positive patients. It is important not to focus only on the environment in these situations. There may be infected or persistently MRSA-colonised staff for example, including those working at night or from agencies. There may also have been observed breakdowns in decontamination, e.g. terminal cleaning, sharing of stethoscopes or pens between patients. Data from screening of these instruments can be used to inform the importance of staff compliance with procedures. Airborne spread is uncommon but has been documented, e.g. on dermatological wards and burns units; if there doubts about the effectiveness of the ventilation of patient single rooms, then screening may be advised by the infection control team.

\section{Ongoing European projects}

MOSAR (Mastering Hospital Antimicrobial Resistance in Europe), a Europe-wide research network co-ordinated by INSERM (the French National Institute of Health and Medical Research) and supported by the European Commission, was established in 2007 and will examine factors determining the dynamics of spread of antimicrobial-resistant bacteria within healthcare facilities and the relative efficacy and medicoeconomic impact of control strategies. Currently, the MOSAR network 
has three clinical trials in progress in ICUs, surgical units and rehabilitation centres (http://www.mosar-sic.org; accessed 27 September 2010).

The SATURN project, a multicentre European project supported by the European Commission, was established in January 2010 (http://www.ec.europa.eu/research/health/infectious-diseases/antimicrobial-drugresistance/index_en.html; accessed 27 September 2010). The network aims to study the impact of antibiotic exposure on the evolution of antimicrobial-resistant bacteria, mainly MRSA and extended-spectrum $\beta$-lactamase-producing Gram-negative bacteria. The overarching rationale of SATURN is to improve methodological standards and to conduct research that will help to understand better the impact of antimicrobial use on acquisition, selection and transmission of antimicrobial-resistant bacteria in different environments, by combining analyses of molecular, individual patient-level and ecological data. The European Centre for Disease Prevention and Control (ECDC) (http://www.ecdc.europa.eu; accessed 27 September 2010) has also contracted groups to produce MRSA guidelines and an assessment of MRSA typing methodologies.

\section{Conclusions}

As concluded in an earlier publication of a consensus statement by experienced practitioners in the field of prevention and control of healthcare-associated infections, including MRSA, "success in preventing and controlling MRSA is dependent on the appropriate attitude and high standards of professionalism among all who deliver healthcare". To do this, appropriate evidence-based strategies are axiomatic. Standard precautions, especially hand hygiene, together with isolation/cohorting, 
education and patient decolonisation in selected situations, are key to the control and prevention of MRSA infection [2]. We now agree and propose that universal or riskbased screening for potential sources of MRSA, whether in the guise of MRSA carriers among patients and HCWs or of MRSA-contaminated surfaces in the health care environment, is an indispensable part of an effective MRSA control strategy in healthcare institutes where MRSA is endemic. The strategy adopted for a screening programme must be established with the active participation of infectious disease physicians, clinical microbiologists, public health officials and economists for a particular country or region.

\section{Acknowledgments}

The meeting was sponsored by the following companies, which gave unrestricted education grants: Astellas Pharma; Becton Dickinson; bioMérieux; Cepheid; Novartis; and Wyeth. This review is based on the proceedings of an expert panel meeting jointly held by the European Society of Clinical Microbiology and Infectious Diseases (ESCMID) and the International Society of Chemotherapy (ISC), 5-6 March 2010, Rome, Italy.

\section{Funding}

None.

\section{Competing interests}

None declared.

\section{Ethical approval}


Not required. 


\section{References}

[1] Humphreys H, Grundmann H, Skov R, Lucet JC, Cauda R. Prevention and control of methicillin-resistant Staphylococcus aureus. Clin Microbiol Infect $2009 ; 15: 120-4$.

[2] MacKenzie FM, Struelens MJ, Towner KJ, Gould IM; ARPAC Steering Group; ARPAC Consensus Conference Participants. Report of the Consensus Conference on Antibiotic Resistance; Prevention and Control (ARPAC). Clin Microbiol Infect 2005;11:938-54.

[3] Struelens MJ, Hawkey PM, French GL, Witte W, Tacconelli E. Laboratory tools and strategies for methicillin-resistant Staphylococcus aureus screening, surveillance and typing: state of the art and unmet needs. Clin Microbiol Infect $2009 ; 15: 112-9$.

[4] Deleo FR, Otto M, Kreiswirth BN, Chambers HF. Community-associated meticillin-resistant Staphylococcus aureus. Lancet 2010;375:1557-68.

[5] Lindsay JA. Genomic variation and evolution of Staphylococcus aureus. Int J Med Microbiol 2010;300:98-103.

[6] European Antimicrobial Resistance Surveillance System. EARSS Annual Report 2008: on-going surveillance of $S$. pneumoniae, S. aureus, E. coli, E. faecium, E. faecalis, K. pneumoniae, $P$. aeruginosa.

http://www.ecdc.europa.eu/en/activities/surveillance/EARSNet/Documents/2008_EARSS_Annual_Report.pdf [access 17 May 2010].

[7] Revised guidelines for the control of epidemic methicillin-resistant Staphylococcus aureus. Report of a combined Working Party of the Hospital Infection Society and British Society for Antimicrobial Chemotherapy. J Hosp Infect 1990;16:351-77. 
[8] Shanson DC. Antibiotic-resistant Staphylococcus aureus. J Hosp Infect $1981 ; 2: 11-36$.

[9] Cookson BD, Phillips I. Epidemic methicillin-resistant Staphylococcus aureus. J Antimicrob Chemother 1988;21(Suppl C):57-65.

[10] Murchan S, Aucken HM, O'Neill G, Ganner M, Cookson BD. Emergence, spread, and characterization of phage variants of epidemic methicillin-resistant Staphylococcus aureus 16 in England and Wales. J Clin Microbiol 2004;42:515460.

[11] Cookson BD; HARMONY Participants. Harmony—-the International Union of Microbiology Societies' European Staphylococcal Typing Network. Euro Surveill 2008;13:pii:18860.

[12] Bootsma MC, Diekmann O, Bonten MJ. Controlling methicillin-resistant Staphylococcus aureus: quantifying the effects of interventions and rapid diagnostic testing. Proc Natl Acad Sci U S A 2006;103:5620-5.

[13] Coia JE, Duckworth GJ, Edwards DI, Farrington M, Fry C, Humphreys H, et al. Guidelines for the control and prevention of meticillin-resistant Staphylococcus aureus (MRSA) in healthcare facilities. J Hosp Infect 2006;63(Suppl 1):S1-44. Erratum in: J Hosp Infect 2006;64:97-8.

[14] Calfee DP, Salgado CD, Classen D, Arias KM, Podgorny K, Anderson DJ, et al. Strategies to prevent transmission of methicillin-resistant Staphylococcus aureus in acute care hospitals. Infect Control Hosp Epidemiol 2008;29(Suppl 1):S62-80.

[15] Safdar N, Bradley EA. The risk of infection after nasal colonization with Staphylococcus aureus. Am J Med 2008;121:310-5. 
[16] Stone SP, Cooper BS, Kibbler CC, Cookson BD, Roberts JA, Medley GF, et al. The ORION statement: guidelines for transparent reporting of outbreak reports and intervention studies of nosocomial infection. J Antimicrob Chemother 2007;59:833-40.

[17] Miller LG, Diep BA. Clinical practice: colonization, fomites, and virulence: rethinking the pathogenesis of community-associated methicillin-resistant Staphylococcus aureus infection. Clin Infect Dis 2008;46:752-60.

[18] Lautenbach E, Nachamkin I, Hu B, Fishman NO, Tolomeo P, Prasad P, et al. Surveillance cultures for detection of methicillin-resistant Staphylococcus aureus: diagnostic yield of anatomic sites and comparison of provider- and patientcollected samples. Infect Control Hosp Epidemiol 2009;30:380-2.

[19] Lautenbach E, Tolomeo P, Nachamkin I, Hu B, Zaoutis TE. The impact of household transmission on duration of outpatient colonization with methicillinresistant Staphylococcus aureus. Epidemiol Infect 2010;138:683-5.

[20] Como-Sabetti KJ, Harriman KH, Fridkin SK, Jawahir SL, Lynfield R. Risk factors for community-associated Staphylococcus aureus infections: results from parallel studies including methicillin-resistant and methicillin-sensitive $S$. aureus compared to uninfected controls. Epidemiol Infect 2010;1:1-11.

[21] Sautter RL, Wells LW. Selective staphylococcal broth. J Clin Microbiol 1990;28:2380-1.

[22] Böcher S, Middendorf B, Westh H, Mellmann A, Becker K, Skov R, et al. Semi-selective broth improves screening for methicillin-resistant Staphylococcus aureus. J Antimicrob Chemother 2010;65:717-20. 
[23] Robicsek A, Beaumont JL, Paule SM, Hacek DM, Thomson RB Jr, Kaul KL, et al. Universal surveillance for methicillin-resistant Staphylococcus aureus in 3 affiliated hospitals. Ann Intern Med 2008;148:409-18.

[24] Jog S, Cunningham R, Copper S, Wallis M, Marchbank A, Vasco-Knight P, et al. Impact of preoperative screening for meticillin-resistant Staphylococcus aureus by real-time polymerase chain reaction in patients undergoing cardiac surgery. $\mathrm{J}$ Hosp Infect 2008;69:124-30.

[25] McGinigle KL, Gourlay ML, Buchanan IB. The use of active surveillance cultures in adult intensive care units to reduce methicillin-resistant Staphylococcus aureus-related morbidity, mortality, and costs: a systematic review. Clin Infect Dis 2008;46:1717-25.

[26] Peterson LR, Diekema DJ. To screen or not to screen for methicillin-resistant Staphylococcus aureus. J Clin Microbiol 2010;48:683-9.

[27] Wassenberg MW, de Wit GA, van Hout BA, Bonten MJ. Quantifying costeffectiveness of controlling nosocomial spread of antibiotic-resistant bacteria: the case of MRSA. PLoS One 2010;5:e11562.

[28] Weber SG, Huang SS, Oriola S, Huskins WC, Noskin GA, Harriman K, et al. Legislative mandates for use of active surveillance cultures to screen for methicillin-resistant Staphylococcus aureus and vancomycin-resistant enterococci: position statement from the Joint SHEA and APIC Task Force. Am J Infect Control 2007;35:73-85.

[29] Mulders MN, Haenen AP, Geenen PL, Vesseur PC, Poldervaart ES, Bosch T, et al. Prevalence of livestock-associated MRSA in broiler flocks and risk factors for slaughterhouse personnel in The Netherlands. Epidemiol Infect 2010;138:74355. 
[30] Cuny C, Nathaus R, Layer F, Strommenger B, Altmann D, Witte W. Nasal colonization of humans with methicillin-resistant Staphylococcus aureus (MRSA) CC398 with and without exposure to pigs. PLos One 2009;4:e6800.

[31] Brown D, Cookson BD. MRSA—laboratory aspects of detection. In: Fluit D, Schmitz F-J, editors. MRSA: current perspectives. Wymondham, UK: Caister Academic Press; 2003. p. 11-29.

[32] West TE, Guerry C, Hiott M, Morrow N, Ward K, Salgado CD. Effect of targeted surveillance for control of methicillin-resistant Staphylococcus aureus in a community hospital system. Infect Control Hosp Epidemiol 2006;27:233-8.

[33] Cookson BD, Burnett J, Butler EA, Wright DA. A hospital computer system as a tool for infection control. In: Bryant J, Roberts J, Windsor P, editors. Current perspectives in health care computing. Weybridge, UK: BJHC Books; 1986.

[34] Ritchie K, Bradbury I, Craig J, Foster L, Kohli H, Iqbal K, et al. The clinical and cost effectiveness of screening for meticillin-resistant Staphylococcus aureus (MRSA). Edinburgh, UK: NHS Quality Improvement Scotland; 2007. Health Technology Assessment Report No. 9.

[35] Reilly JS, Stewart S, Christie P, Allardice G, Smith A, Masterton R, et al. Universal screening for meticillin-resistant Staphylococcus aureus: interim results from the NHS Scotland pathfinder project. J Hosp Infect 2010;74:35-41.

[36] Health Protection Scotland. NHS Scotland MRSA Screening Pathfinder Programme Interim Report 2009. Edinburgh, UK: Health Protection Scotland, National Services Scotland; 2009.

[37] Cookson B, Peters B, Webster M, Phillips I, Rahman M, Noble W. Staff carriage of epidemic methicillin-resistant Staphylococcus aureus. J Clin Microbiol 1989;27:1471-6. 
[38] Albrich WC, Harbarth S. Health-care workers: source, vector, or victim of MRSA? Lancet Infect Dis 2008;8:289-301.

[39] Vonberg R-P, Stamm-Balderjahn S, Hansen S, Zuschneid I, Ruden H, Behnke $M$, et al. How often do asymptomatic healthcare workers cause methicillinresistant Staphylococcus aureus outbreaks? A systematic evaluation. Infect Control Hosp Epidemiol 2006;27:1123-7.

[40] Tacconelli E, De Angelis G, Cataldo MA, Mantengoli E, Spanu T, Pau A, et al. Antibiotic usage and risk of colonization and infection with antibiotic-resistant bacteria: a hospital population-based study. Antimicrob Agents Chemother 2009;53:4264-9.

[41] Harbarth S, Fankhauser C, Schrenzel J, Christenson J, Gervaz P, BandieraClerc C, et al. Universal screening for methicillin-resistant Staphylococcus aureus at hospital admission and nosocomial infection in surgical patients. JAMA 2008;299:1149-57.

[42] Spicer WJ. Three strategies in the control of staphylococci including methicillin-resistant Staphylococcus aureus. J Hosp Infect 1984;5(Suppl A):45-9.

[43] Simoens S, Ophals E, Schuermans A. Search and destroy policy for methicillin-resistant Staphylococcus aureus: cost-benefit analysis. J Adv Nurs $2009 ; 65: 1853-9$.

[44] Gemmell CG, Edwards DI, Fraise AP, Gould FK, Ridgway GL, Warren RE; Joint Working Party of the British Society for Antimicrobial Chemotherapy, Hospital Infection Society and Infection Control Nurses Association. Guidelines for the prophylaxis and treatment of methicillin-resistant Staphylococcus aureus (MRSA) infections in the UK. J Antimicrob Chemother 2006;57:589-608. 
[45] Gould FK, Brindle R, Chadwick PR, Fraise AP, Hill S, Nathwani D, et al.; MRSA Working Party of the British Society for Antimicrobial Chemotherapy. Guidelines (2008) for the prophylaxis and treatment of methicillin-resistant Staphylococcus aureus (MRSA) infections in the United Kingdom. J Antimicrob Chemother 2009;63:849-61.

[46] Evans HL, Dellit TH, Chan J, Nathens AB, Maier RV, Cuschieri J. Effect of chlorhexidine whole-body bathing on hospital-acquired infections among trauma patients. Arch Surg 2010;145:240-6.

[47] Coates T, Bax R, Coates A. Nasal decolonization of Staphylococcus aureus with mupirocin: strengths, weaknesses and future prospects. J Antimicrob Chemother 2009;64:9-15.

[48] Bode LG, Kluytmans JA, Wertheim HF, Bogaers D, Vandenbroucke-Grauls $\mathrm{CM}$, Roosendaal $\mathrm{R}$, et al. Preventing surgical-site infections in nasal carriers of Staphylococcus aureus. N Engl J Med 2010;362:9-17.

[49] Tacconelli E, De Angelis G, de Waure C, Cataldo MA, La Torre G, Cauda R. Rapid screening tests for meticillin-resistant Staphylococcus aureus at hospital admission: systematic review and meta-analysis. Lancet Infect Dis 2009;9:54654.

[50] Wernitz MH, Swidsinski S, Weist K, Sohr D, Witte W, Franke KP, et al. Effectiveness of a hospital-wide selective screening programme for methicillinresistant Staphylococcus aureus (MRSA) carriers at hospital admission to prevent hospital-acquired MRSA infections. Clin Microbiol Infect 2005;11:457-65.

[51] Strausbaugh LJ, Siegel JD, Weinstein RA. Preventing transmission of multidrug-resistant bacteria in health care settings: a tale of 2 guidelines. Clin Infect Dis 2006;42:828-35. 
[52] Farr BM. Political versus epidemiological correctness. Infect Control Hosp Epidemiol 2007;28:589-93.

[53] Diekema DJ, Edmond MB. Look before you leap: active surveillance for multidrug-resistant organisms. Clin Infect Dis 2007;44:1101-7.

[54] van Rijen MM, Bonten M, Wenzel RP, Kluytmans JA. Intranasal mupirocin for reduction of Staphylococcus aureus infections in surgical patients with nasal carriage: a systematic review. J Antimicrob Chemother 2008;61:254-61.

[55] Harbarth S, Liassine N, Dharan S, Herrault P, Auckenthaler R, Pittet D. Risk factors for persistent carriage of methicillin-resistant Staphylococcus aureus. Clin Infect Dis 2000;31:1380-5.

[56] Ammerlaan HS, Kluytmans JA, Wertheim HF, Nouwen JL, Bonten MJ. Eradication of methicillin-resistant Staphylococcus aureus carriage: a systematic review. Clin Infect Dis 2009;48:922-30.

[57] Revised guidelines for the control of methicillin-resistant Staphylococcus aureus infections in hospitals. British Society for Antimicrobial Chemotherapy, Hospital Infection Society and the Infection Control Nurses Association. J Hosp Infect 1998;39:253-90. Erratum in: J Hosp Infect 1999;42:83.

[58] Cookson B, Peters B, Webster M, Phillips I, Rahman M, Noble W. Staff carriage of epidemic methicillin-resistant Staphylococcus aureus. J Clin Microbiol $1989 ; 27: 1471-6$.

[59] Enoch DA, Karas JA, Slater JD, Emery MM, Kearns AM, Farrington M. MRSA carriage in a pet therapy dog. $\mathrm{J}$ Hosp Infect 2005;60:186-8.

[60] Lefebvre SL, Weese JS. Contamination of pet therapy dogs with MRSA and Clostridium difficile. J Hosp Infect 2009;72:268-9. 
[61] Boyce JM. Environmental contamination makes an important contribution to hospital infection. J Hosp Infect 2007;65(Suppl 2):50-4.

[62] Sax H, Allegranzi B, Uçkay I, Larson E, Boyce J, Pittet D. 'My five moments for hand hygiene': a user-centred design approach to understand, train, monitor and report hand hygiene. J Hosp Infect 2007;67:9-21. 


\section{Table 1}

Risk factors for colonisation with meticillin-resistant Staphylococcus aureus (MRSA) at hospital admission

HCA-MRSA infection
- Previously colonised or infected, or their close contacts

- Previous therapy with quinolones, cephalosporins or carbapenems

- Previous hospitalisation (especially in a hospital known to have high incidence of MRSA), surgery or healthcare contact

- Previous MRSA colonisation or infection

- Dialysis

- Indwelling bladder or vascular device at home

- Underlying chronic illness

- i.v. drug abuse

- Residency in LTCFs or NHs, i.v. therapy, or specialised nursing at home

- Open wounds (pressure sores, varicose ulcers)

- International or interhospital transfers from high-risk location
CA-MRSA infection

- Previously colonised or infected, or their close contacts

- Previous antibiotic therapy with quinolones or macrolides

- Underlying chronic illness

- Livestock/animal workers, including veterinary staff

\section{Without risk factors}

Groups with a higher incidence:

Athletes

Military personnel

Male having sex with male

Prison inmates

i.v. drug users

Homeless persons

Native Americans

Pacific Islanders

Children in day-care

programmes

Recent travel to an endemic area such as North America 
HCA-MRSA, healthcare-associated MRSA; CA-MRSA, communityacquired/associated MRSA; i.v. intravenous; LTCF, long-term-care facility; $\mathrm{NH}$, nursing home. 